\title{
Comparative measurements of water vapor fluxes over a tall forest using open- and closed-path eddy covariance system
}

\author{
J. B. Wu, X. Y. Zhou, A. Z. Wang, and F. H. Yuan \\ State Key Laboratory of Forest and Soil Ecology, Institute of Applied Ecology, Chinese Academy \\ of Sciences, Shenyang, China \\ Correspondence to: J. B.Wu (wujb@iae.ac.cn)
}

Received: 9 February 2015 - Published in Atmos. Meas. Tech. Discuss.: 7 May 2015

Revised: 11 September 2015 - Accepted: 19 September 2015 - Published: 7 October 2015

\begin{abstract}
Eddy covariance using infrared gas analyzes has been a useful tool for gas exchange measurements between soil, vegetation and the atmosphere. So far, comparisons between the open- and closed-path eddy covariance (CP) system have been extensively made on $\mathrm{CO}_{2}$ flux estimations, while lacking in the comparison of water vapor flux estimations. In this study, the specific performance of water vapor flux measurements of an open-path eddy covariance (OP) system was compared against a CP system over a tall temperate forest in northeastern China. The results show that the fluxes from the OP system $\left(L E_{\mathrm{op}}\right)$ were generally greater than the $L E_{\mathrm{cp}}$ though the two systems shared one sonic anemometer. The tube delay of closed-path analyzer depended on relative humidity, and the fixed median time lag contributed to a significant underestimation of $L E_{\mathrm{cp}}$ between the forest and atmosphere, while slight systematic overestimation was also found for covariance maximization method with single broad time lag search window. After the optimized time lag compensation was made, the average difference between the $30 \mathrm{~min} L E_{\mathrm{op}}$ and $L E_{\mathrm{cp}}$ was generally within $6.0 \%$. Integrated over the annual cycle, the CP system yielded a $5.1 \%$ underestimation of forest evapotranspiration as compared to the OP system measurements ( $493 \mathrm{vs} .469 \mathrm{~mm} \mathrm{yr}^{-1}$ ). This study indicates the importance to estimate the sampling tube delay accurately for water vapor flux calculations with closed-path analyzers, and it also suggests that some of the imbalance of the surface energy budget in flux sites is possibly caused by the systematic underestimation of water vapor fluxes measured with closed-path eddy covariance systems.
\end{abstract}

\section{Introduction}

Following the global changes, the surging interest in biotic feedback to global climate changes has led to an explosion in the research of terrestrial carbon and water cycle. Quantifying the water vapor fluxes helps understanding the components of the energy and water budgets in terrestrial ecosystem, and also helps to validate satellite-based estimates of regional and global evapotranspiration (Vinukollu et al., 2011; Consoli and Vanella, 2014). Hence in the scientific community, great efforts have been made to reduce the systematic errors and biases in water vapor flux estimations in terrestrial ecosystem.

Currently, the vertical water vapor fluxes between terrestrial ecosystem and the atmosphere are often measured using the eddy-covariance technique (Aubinet et al., 2000; Baldocchi et al., 2001). Long-term and continuous evapotranspiration data measured with this method, coupled with micrometeorological data, allows analysis of the factors controlling water vapor exchange between terrestrial vegetation and the atmosphere. Practically, for the eddy covariance method, the vertical wind speed components are generally measured with sonic anemometers, while water vapor concentrations may be measured in situ using an open-path infrared gas analyzer or by passing air through a sampling tube to the ground and then measured using a closed-path analyzer. The former quantifies water vapor concentrations close to the point where the vertical wind speed is measured. The latter quantifies water vapor concentrations of air pumped through a tube with intake point close to the anemometer. These two measurement designs are the so-called open-path (OP) and closed-path (CP) techniques. Due to the physical limitations of the instruments and the non-ideal observation environ- 
ment, there are some uncertainties associated with both of these two methods (Haslwanter et al., 2009; Leuning and Judd, 1996). Additionally, the differential procedure of postprocessing of eddy covariance data from OP- and CP system also leads to potential source of bias in calculated fluxes. All these have been widely discussed in the FLUXNET community (e.g., Lee, 1998; Leuning and Moncrieff, 1990; Leuning and King, 1992; Leuning and Judd, 1996).

The most common and necessary corrections for the eddy-covariance based $\mathrm{CO}_{2} / \mathrm{H}_{2} \mathrm{O}$ flux measurements have been described by Massman and Lee (2002) as (1) sonic anemometer tilt correction, (2) compensation for density fluctuations, and (3) spectral corrections. Webb et al. (1980) and Leuning et al. (1990) suggested that the measured flux should be corrected for density fluctuations induced by concurrent fluxes of latent and sensible heat. This correction is generally more remarkable for OP systems, because with $\mathrm{CP}$ systems, temperature fluctuations could dampen out as air passes through the sampling tube (Aubinet et al., 2000). However, a well-known demerit of the CP system is that sampling air through tube attenuates fluctuations of gas concentration. This effect may cause substantial underestimates of turbulent fluxes (Leuning and Moncreiff, 1990; Massman, 1991). Accordingly, several correction methods (e.g., Leuning and King, 1992; Fratini et al., 2012) were suggested to provide quantitative corrections of $\mathrm{CO}_{2}$ and $\mathrm{H}_{2} \mathrm{O}$ flux measurements with CP system, and after correction, most of the results suggested that the measured $\mathrm{CO}_{2}$ fluxes by OP system were quite consistent with the fluxes measured by CP system (e.g., Suyker and Verma, 1993; Lee et al., 1994; Ibrom et al., 2007b).

Compared to the large number of studies on intercomparisons of $\mathrm{CO}_{2}$ fluxes based on open- and closed-path system (e.g., Kondo and Tsukamoto, 2012; Jarvi et al., 2009; Yasuda and Watanabe, 2001; Leuning and King, 1992), however, comparisons of these two systems for water vapor flux measurements are very rare, with only several studies have been published till date. To our knowledge, Haslwanter et al. (2009) made a long-term water vapor flux measurements above a temperate mountain grassland and found that the $\mathrm{CP}$ system tended to underestimate water vapor fluxes when compared to OP system. Therefore it is critical to further examine whether the OP-system-measured vapor water fluxes are consistent with that of the CP system, especially in the forest flux sites with relatively high water vapor exchange rates.

In the recent decades, both $\mathrm{CP}$ and $\mathrm{OP}$ systems have widely used in the carbon and water cycle studies. It is important to explore their systematic bias by conducting intercomparisons over different ecosystem types for accurately quantifying water vapor exchange between terrestrial vegetation and the atmosphere. The aim of the present study is to assess the bias between $\mathrm{OP}$ and $\mathrm{CP}$ system in water vapor flux measurements by analyzing a year-round data set from an old-growth temperate forest in northeastern China, where concurrent $\mathrm{OP}$ and $\mathrm{CP}$ flux measurements have been performed since 2002. The secondary purpose is to reexamine the effects of tube delay of closed path gas analyzer on water vapor flux estimations.

\section{Materials and methods}

\subsection{Site description}

The forest experimental site is located within the National Natural Conservation Park of the Changbai Mountains, northeastern China $\left(42^{\circ} 24^{\prime} 90^{\prime \prime} \mathrm{N}, 128^{\circ} 50^{\prime} 45^{\prime \prime} \mathrm{E}\right)$, and where is a monsoon-influenced, temperate, continental climatic zone. Its annual average temperature is $3.6^{\circ}$ and precipitation is $677 \mathrm{~mm}$. The terrain that surrounds the tower is flat with an elevation of $738 \mathrm{~m}$. The forest stand is dominantly covered with an over 260-year-old mixed stand of Korean pine (Pinus koraiensis), tuan linden (Tilia amurensis), and other interspersed broadleaved tree species. The canopy has a mean height of approximately $27 \mathrm{~m}$ and maximum leaf area index of 6.5. The growing season is from May through September.

\subsection{Observation system}

The water vapor fluxes were measured using the eddy covariance method since year of 2002 in the forest site. The three wind components and the virtual temperature were measured with a three-dimensional sonic anemometer (CSAT3, Campbell Sci., Inc., USA) at $40 \mathrm{~m}$ above ground. $\mathrm{CO}_{2}$ and water vapor densities were concurrently measured with an $\mathrm{OP}(\mathrm{Li}-$ 7500, Li-Cor, Lincoln, NE, USA) and a CP (Li-7000, LiCor, Lincoln, NE, USA) infrared gas analyzer. The openpath analyzer was installed slightly tilted away from the vertical direction to facilitate water run-off. The closed-path analyzer was calibrated twice a day with standard $\mathrm{CO}_{2}$ gases (420.0 ppm, balanced with nitrogen) and high purity nitrogen gas $(99.999 \%)$. Calibration of the open-path analyzer was carried out yearly before the growing season started. Calibrations of the water vapor span were performed simultaneously using a dew point generator (LI-610, Li-Cor Biogeosciences, Lincoln, NE, USA) for both open- and closed-path analyzers.

In the CP system air was pumped from the inlet displaced at the vicinity of the anemometer measurement point and drawn down through a sampling tube to the closed-path gas analyzer located in a building. Sample air was drawn at a flow rate of $7.4 \mathrm{~L} \mathrm{~min}^{-1}$ from the air intake through a teflon tube with $47 \mathrm{~m}$ length and $4 \mathrm{~mm}$ inner diameter. The sample line was heated (self-regulating) to dampen out temperature fluctuations in the tube. The nominated time lag for a scalar that does not interact with the tube is $4.8 \mathrm{~s}$. The open-path analyzer was setup near the same sonic anemometer. Data were recorded at $10 \mathrm{~Hz}$ sampling rate through a CR5000 data logger. A precipitation gauge (model 52203, RM. Young, Traverse City, MI, USA) was mounted on top of the tower. Air 
Table 1. Data coverage of water vapor flux data from the open- and closed-path eddy covariance system recorded in the observation year of 2003 at the Changbai Mountains forest flux site. Technical issues include power failure, equipments maintenance and calibration. The stationarity test filtered out flux data calculated for a 30 min interval deviate more than $30 \%$ from the mean of the covariance of 5 min subperiods (Foken and Wichura, 1996).

\begin{tabular}{llllll}
\hline $\begin{array}{l}\text { Instrument } \\
\text { systems }\end{array}$ & $\begin{array}{l}\text { Technique } \\
\text { issues }\end{array}$ & $\begin{array}{l}\text { Interference of } \\
\text { precipitation } \\
\text { or droplets } \\
(\mathrm{RH}>95 \%)\end{array}$ & $\begin{array}{l}\text { Integral turbu- } \\
\text { lence and sta- } \\
\text { tionary tests }\end{array}$ & $\begin{array}{l}\text { Out-of- } \\
\text { threshold } \\
\text { values with no } \\
\text { clear reason }\end{array}$ & Valid data \\
\hline OPEC & $4.1 \%$ & $8.2 \%$ & $13.5 \%$ & 1.7 & $72.5 \%$ \\
CPEC & $3.5 \%$ & $5.6 \%$ & $15.7 \%$ & 1.0 & $74.2 \%$ \\
\hline
\end{tabular}

temperature and relative humidity were measured with HMP45C sensors (Vaisala, Helsinki, Finland), with sensors placed at $2.5,16,22,26,32,40,50$ and $60 \mathrm{~m}$, respectively.

\subsection{Data processing and quality control}

In this study year-round eddy covariance measured data were presented. The raw water vapor fluxes were calculated from the mean covariance between vertical velocity $\left(w^{\prime}\right)$ and the respective scalar for each $30 \mathrm{~min}$ interval. The time lags of $\mathrm{CP}$ system between measured vertical wind speed and water vapor concentration were calculated by using covariance maximization method (Fan et al., 1990) with a single lag search window, as well as with optimized time lags for different classes of relative humidity (i.e., pre-evaluate the nominal time lags and plausibility search windows for 10 classes of relative humidity in the range of 0 to $100 \%$.

Axis rotation for tilt correction was carried out with linear detrended raw time series, using the revised planar fit method according to van Dijk et al. (2004). Comparison of rotated and non-rotated fluxes showed small differences (averagely less than $2.5 \%$ ) for both OP and CP system. All sensors are affected by high-frequency damping due to several reasons including instrument time response limitation, sensors separation, etc. Closed-path systems are specifically affected by the damping due to fluctuation attenuation in the sampling tube. Therefore, the spectral corrections are especially important for closed-path analyzers. In this study, spectral corrections for high-pass filtering and low-pass filtering of closed-path analyzer were implemented following Moncrieff et al. (2004), and Fratini et al. (2012), respectively. For OP system, spectral losses due to instrument separations were account for according to Horst and Lenschow (2009). The results showed that the corrected $L E$ values were generally on the order of $6.2-11.0 \%$ of raw fluxes, while the CP system measured $L E$ received considerable spectral corrections ranged from 6.7 to $11.5 \%$ of the raw flux signal. During this period, the WPL correction (i.e. Webb-PearmanLeuning correction Webb et al., 1980) for the open-path measurements was averaged to be $9.2 \%$ and the WPL terms for the closed-path measurements was equal to around $1.0 \%$ of the raw flux signal (Ibrom et al., 2007b). The surface self- heating correction of the OP system in cold environments (Burba et al., 2008) was less crucial, with the average overestimation was less than $1.5 \%$ of $L E_{\mathrm{op}}$. Calculated fluxes were subject to the integral turbulence and stationarity tests following Foken and Wichura (1996) with three classes of quality flags for each $30 \mathrm{~min}$ interval, from 1 to 3 . The data of classes 1-2 were used in this study, and class 3 were excluded as abnormal.

In order to obtain continuous flux time series, the following gap filling procedure was employed: all gaps less than four consecutive $30 \mathrm{~min}$ intervals were filled by linear interpolation between the nearest measured data points, continuous gaps longer than $2 \mathrm{~h}$ were filled using the linear ordinary least squares regression relationships between halfhourly water vapor fluxes and short-wave radiation. These relationships were developed using data grouped according to the following phenological stages: growing season (MaySeptember), non-growing season (November-March), and two transition periods (April, October). When both meteorological data and eddy flux data were not available, only daily evapotranspiration values were filled using linear relationship between water vapor exchange and available energy.

Generally, high-quality eddy flux measurement requires high and continuous data coverage in long-term observation. Hence, the available data set obtained from the open- and closed-path system during the year-round observation were checked. As described in Table 1, application of all filtering criteria resulted in final data coverage of $72.5 \%$ for water vapor flux estimated from the OP system. The routine friction velocity $\left(u^{*}\right)$ filtering for $\mathrm{CO}_{2}$ fluxes was not applied to the water vapor data sets, considering that the molecular weight of water vapor is far less than that of air. Specifically, technical issues (power failure, equipments maintenance and calibration) during the measurements removed $4.1 \%$ of the measurement data, while a larger percentage $(8.2 \%)$ of the out-of-range data was mainly caused by interference of droplets in the optical path of the instrument, as indicated by the synchronously recorded rainfall data, as well as the recorded negative latent heat fluxes during the nighttime. This suggests that installing the open-path analyzer at an angle away from the vertical direction and as well 

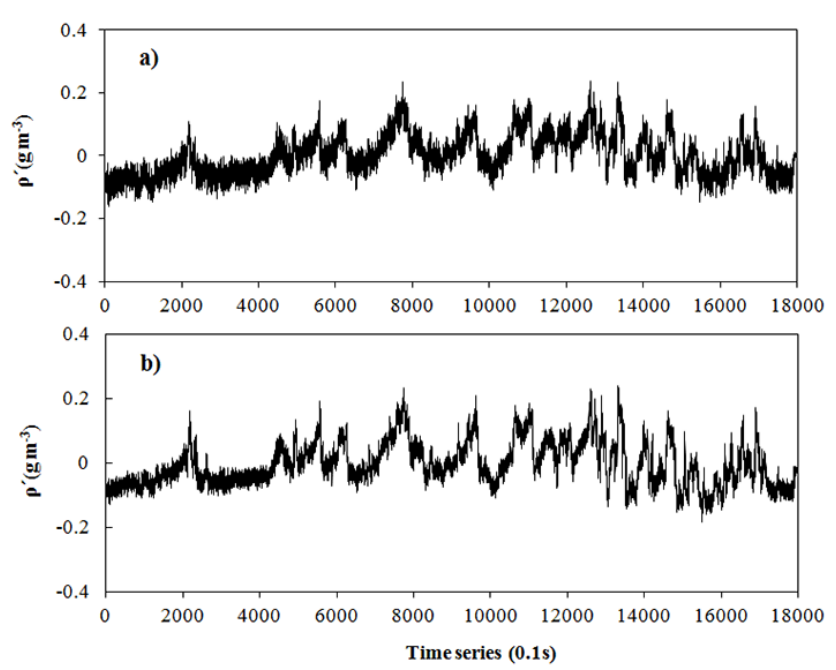

Figure 1. A typical example of the turbulent fluctuations for water vapor concentration $\left(\rho^{\prime}\right)$ measured by the open- (a) and closed-path gas analyzer (b). These fluctuations are plotted as a deviation from the raw data at $10 \mathrm{~Hz}$, and the time series data of closed-path infrared gas analyzer were set back $9.1 \mathrm{~s}$ to eliminate the effect of tube delay.

Table 2. Variable time lag windows for water vapor in a $47 \mathrm{~m}$ sampling tube of closed-path system within different relative humidity ranges at Changbai Mountains forest site. For sound statistical analysis, the minimum number of available data for time lag analysis was 30 in each class. If the filtered number of data is less than 30 , its time lags are set equal to that of the adjacent class.

\begin{tabular}{crrrrr}
\hline class & RH range & $\begin{array}{r}\text { Median } \\
\text { value }(\mathrm{s})\end{array}$ & $\begin{array}{r}\mathrm{Lag}_{\min } \\
(\mathrm{s})\end{array}$ & $\begin{array}{r}\mathrm{Lag}_{\max } \\
(\mathrm{s})\end{array}$ & $\begin{array}{r}\text { available } \\
\text { data set }\end{array}$ \\
\hline 1 & $10-20 \%$ & 5.57 & 5.27 & 5.81 & 18 \\
2 & $20-30 \%$ & 5.65 & 5.30 & 5.93 & 195 \\
3 & $30-40 \%$ & 6.03 & 5.42 & 6.53 & 341 \\
4 & $40-50 \%$ & 6.70 & 5.95 & 7.97 & 557 \\
5 & $50-60 \%$ & 7.94 & 6.35 & 10.45 & 905 \\
6 & $60-70 \%$ & 9.10 & 6.87 & 18.92 & 896 \\
7 & $70-80 \%$ & 13.25 & 9.47 & 29.70 & 639 \\
8 & $80-90 \%$ & 17.68 & 14.41 & 34.63 & 432 \\
9 & $90-100 \%$ & 27.17 & 17.11 & 39.94 & 199 \\
\hline
\end{tabular}

as coating with a hydrophobic wax couldn't totally prevent the deposition of droplets on the optical windows of the analyzer. To remove these abnormal data caused by condensed water, the measured fluxes were excluded during precipitation ( $30 \mathrm{~min}$ precipitation $>0.5 \mathrm{~mm}$ ) and high relative humidity periods (mean relative humidity $>95 \%$ ). Water vapor flux estimates from the CP system met the screening criteria was $74.2 \%$. There is a correspondingly larger fraction of unaccepted CP flux values too, with most of the rejected data $(15.7 \%)$ mainly due to failing in the integral turbulence and stationarity tests.

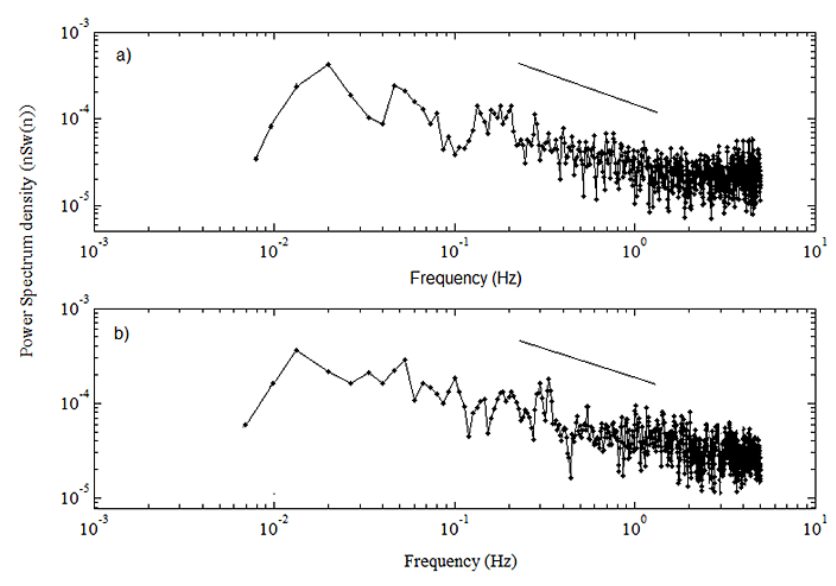

Figure 2. Power spectra of the measured water vapor concentration by the open- (a) and closed-path gas analyzer (b), where $n$ is non-dimensional frequency. The solid lines indicates $-2 / 3$ spectral decay for reference.

\section{Results}

\subsection{Comparison of water vapor density measurements}

The raw signal of water vapor concentration fluctuations measured with the open- and closed-path analyzers were compared with data derived over a typical clear day. As shown in Fig. 1 (the data presented in Fig. 1 can be found in the Supplement), the fluctuations in water vapor density recorded from the OP analyzer are similar to those from the $\mathrm{CP}$ analyzer, and both follow the same fluctuation trends. The former is generally greater than that of the later. Visually it can be seen that the $\mathrm{CP}$ analyzer did not capture the sharp ripples as found in the raw data recorded by the OP analyzer. This indicates that the water vapor concentration fluctuations were possibly attenuated by the long sampling tube of $\mathrm{CP}$ system. Overall, the magnitude of fluctuations in water vapor densities measured from OP system is approximately 1.2 times higher than that from the CP system. Figure 2 shows the power spectra of the measured water vapor concentration. It shows that the spectra peak around $0.1-0.01 \mathrm{~Hz}$, which indicates that the larger eddies dominate the water vapor exchange over forest canopy. The power spectra for OP analyzer exhibit slight flattening at high frequency (Fig. 2a), which is indicative of white noise introduced by the sensor. Generally, the spectra is similar between these two systems, and the high frequency attenuation for $\mathrm{CP}$ analyzer is not significantly different from that of OP analyzer, which verifies the above result that both sets of measurements received similar magnitude of spectral corrections of the raw flux signal. 


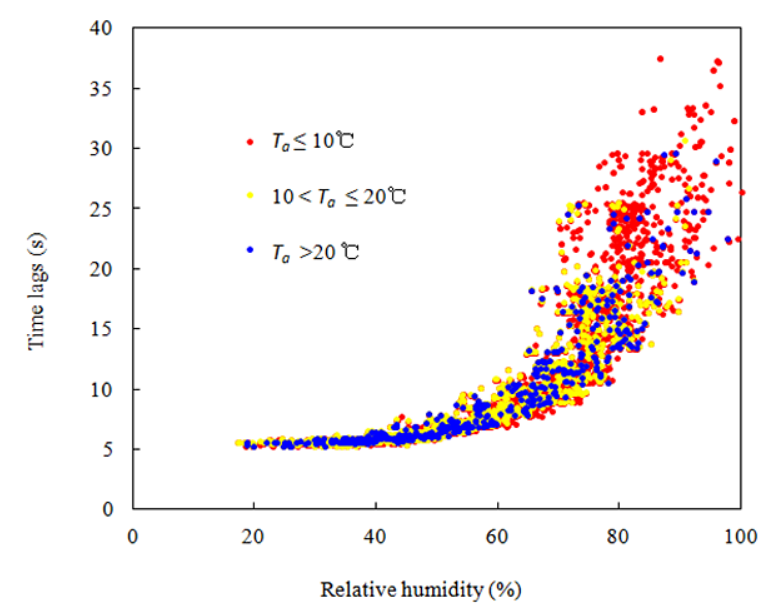

Figure 3. The actual tube delay for water vapor measurement in a $47 \mathrm{~m}$ sampling tube of closed-path system. The time lags were calculated using the maximum cross-correlation method combining with the optimized time lag search windows presented in Table 2.

\subsection{Comparison of different lag time compensation methods}

Table 2 shows the results of a time lag optimization procedure using four months of data. The nominal, minimum, and maximum time lags were calculated as a function of relative humidity $(\mathrm{RH})$. The tube delay of $\mathrm{CP}$ system to crosscorrelation peak was observed to depend strongly on RH. For example, the nominal lag time for this $47 \mathrm{~m}$ sampling tube was $6.7 \mathrm{~s}$ when $\mathrm{RH}$ was within the range of $40-50 \%$, which is greater than the theoretical lag time $(4.8 \mathrm{~s})$ calculated according to the flow rates, tube inner diameter and length. As the relative humidity increased to over $90 \%$, the lag time increased to around $27.2 \mathrm{~s}$. Figure 3 shows the optimized time lags during the study period calculated using the above time lag search windows in different RH classes. The maximal actual time lag is $37.6 \mathrm{~s}$ when RH goes to $100 \%$ and $5.3 \mathrm{~s}$ when $\mathrm{RH}$ goes to $10 \%$. The latter is very close to the theoretical lag time. The classified data in Fig. 3 also demonstrate that the lag-time values generally decreased with the increasing of air temperature, which suggests that the residence time of water vapor in the sampling line is also a function of temperature. This is naturally consistent with the findings that lag times vary as a function of latent fluxes (Nordbo et al., 2012).

The time lag of closed-path system for water vapor measurements is related to relative humidity, and which means that the fixed time lag could cause a systematic underestimation of $L E_{\mathrm{cp}}$. Figure 4 gives an illustration of measured $L E_{\text {cp }}$ estimated with optimized time lags against $L E_{\text {cp }}^{\prime}$ estimated with a fixed median tube delay $(8.6 \mathrm{~s}$, the median time lags derived from the available data set). The absolute differences between $L E_{\mathrm{cp}}$ and $L E_{\mathrm{cp}}^{\prime}$ were largest during midday and were up to $30.8 \mathrm{~W} \mathrm{~m}^{-2}$, with the mean relative differences less than $5.0 \%$. During nighttime, the absolute differ-

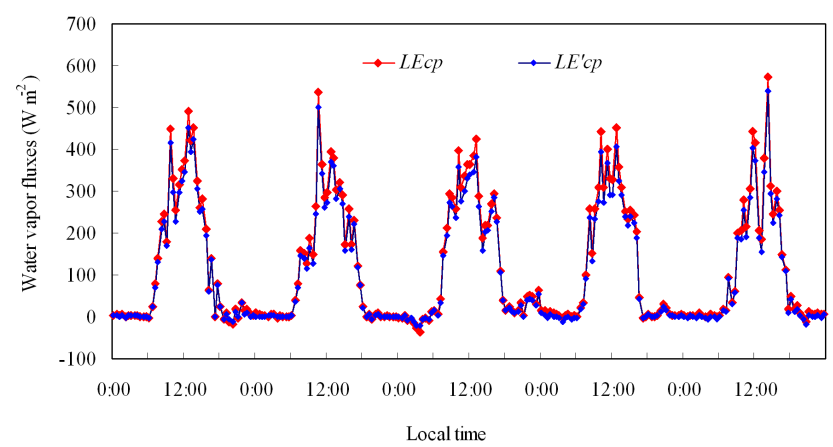

Figure 4. Comparison of water vapor fluxes calculated with a fixed lag time and time lags estimated from the optimized covariance maximum method during the observation period (17-21 August 2003).

ences were smaller ( 0.2 to $9.3 \mathrm{~W} \mathrm{~m}^{-2}$ ) but the relative differences were generally greater than $10 \%$. This indicated that the fixed tube delay tends to severely underestimate nighttime and early morning water vapor fluxes, as the recorded meteorological data show that high humidity conditions often occurred during these periods. Overall, when the fixed median value is used, the 5 days of accumulated $L E_{\mathrm{cp}}$ is on average of $5.3 \%$ underestimated.

The water vapor fluxes calculated with the optimized time lags were also compared with the conventional covariance maximization procedure, and slight overestimation was also found for covariance maximization method with single time lag search window. The cases when the time lags mismatched between the single window and the 10 classified windows cover $7.2 \%$ of the data set. When the former values are used, $L E_{\mathrm{cp}}$ is on average of $1.2 \%$ overestimated (data was not shown, because it highly overlapped with the measured values of $L E_{\mathrm{cp}}$ ). Using the conventional covariance maximization procedure, a plausible time lag window is defined with a single low- and high threshold, which generally is a broad search window to cover all of the possible time lags (Ibrom et al., 2007b), while without consideration of the plausible time lag at certain RH level. This increases the possibility that unrealistic time lags are detected and hence results in flux overestimations.

\subsection{Comparison of $L E_{\mathrm{op}}$ and $L E_{\mathrm{cp}}$}

The half-hourly water vapor fluxes measured with the openand closed-path eddy covariance system were compared with only field measured data derived over 5 continuous days when no rain occurred. $L E_{\mathrm{op}}$ and $L E_{\mathrm{cp}}$ values varied in the range of -32 to $472 \mathrm{~W} \mathrm{~m}^{-2}$ and -15 to $450 \mathrm{~W} \mathrm{~m}^{-2}$, respectively (Fig. 5a). There is generally good agreement of diurnal course between $L E_{\mathrm{op}}$ and $L E_{\mathrm{cp}}$, but consistent differences in magnitude are apparent during observation period. The absolute differences between the two eddy covariance systems increased with the increase water exchange rates, but the rel- 

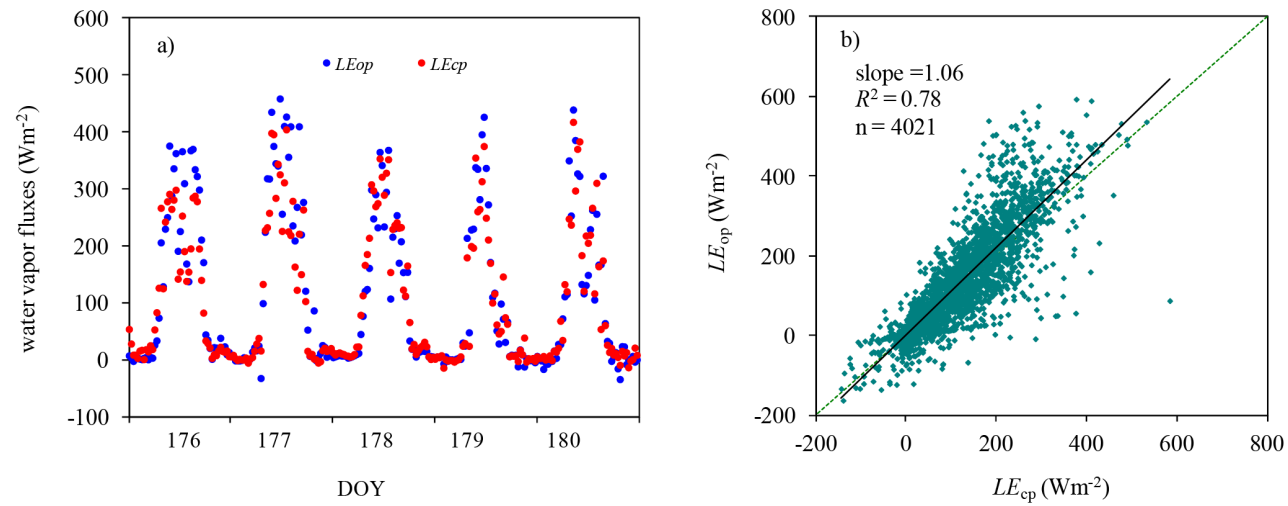

Figure 5. Comparison of diurnal course of water vapor fluxes derived from open- and closed path system at the Changbai Mountains forest site (a), and open-path system measured water vapor fluxes $\left(L E_{\mathrm{op}}\right)$ vs. closed-path $\left(L E_{\mathrm{cp}}\right)$ water vapor fluxes in the whole growing season of 2003 (b).
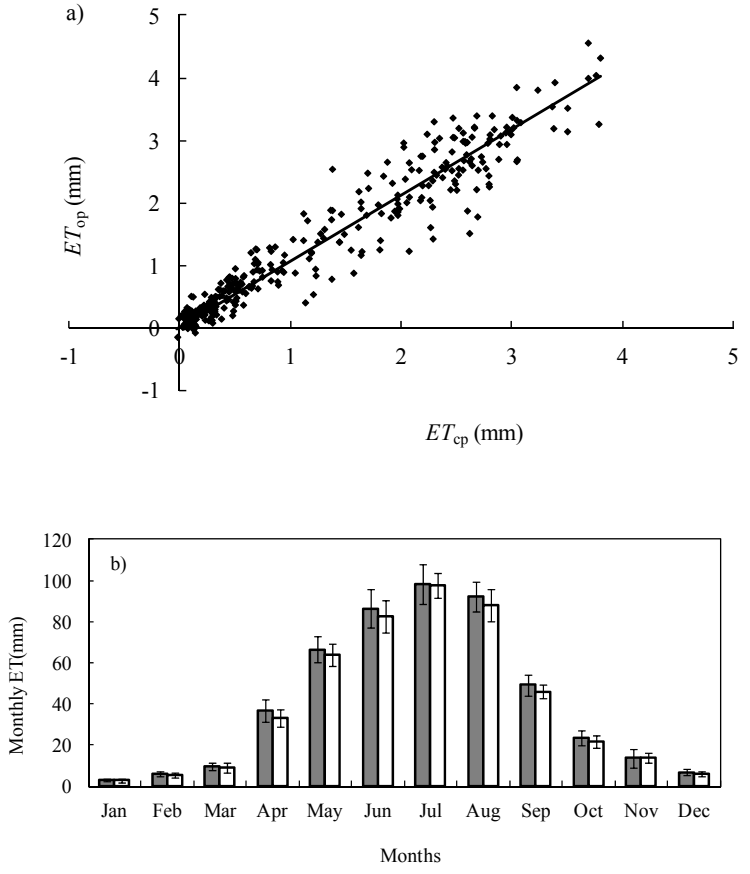

Figure 6. Open-path system measured daily evapotranspiration $\left(\mathrm{ET}_{\mathrm{op}}\right)$ vs. closed-path daily evapotranspiration $\left(\mathrm{ET}_{\mathrm{cp}}\right)$ during the observation period at the Changbai Mountains forest site (a). The analysis was based on 244 data points. Year-round comparative measurements of monthly ET rates by using open- (filled bars) and closed path system (open bars) at the Changbai Mountains forest flux site (b). Error bars refer to the random uncertainty of fluxes. Latent heat fluxes were converted from energy to water vapor units by multiplication with the latent heat of vaporization.

ative differences were decreased. The absolute differences of measured water vapor fluxes were largest during midday and were up to $80 \mathrm{~W} \mathrm{~m}^{-2}$, with the mean relative difference was around $5.7 \%$. During nighttime, the absolute differences were smaller (less than $10.0 \mathrm{~W} \mathrm{~m}^{-2}$ ) but the relative differences were much larger. Overall, the accumulation of water vapor fluxes estimated from $\mathrm{CP}$ system over the 5 days was averagely underestimated by $6.0 \%$ compared to that of OP system.

Figure $5 \mathrm{~b}$ shows the comparison of the $30 \mathrm{~min}$ water vapor fluxes as measured by OP- and $\mathrm{CP}$ system during the whole growing season. The underestimate biases of water vapor fluxes measured with the CP system relative to OP system measurements are remarkable. The underestimation of $L E_{\mathrm{cp}}$ is significant through most of period and the CP system measured water vapor fluxes are estimated to be on average of $5.6 \%$ lower than that of OP system measurements.

According to the year round measurements, the water vapor exchange rates obtained from the $\mathrm{CP}$ system agreed well with the OP system measurements in seasonal pattern, as shown in Fig. 6. Water vapor exchange rates at the site varied largely during the observation year. The maximum daily evapotranspiration was up to $4.6 \mathrm{~mm} \mathrm{day}^{-1}$ in summer, and the typical values of summertime evapotranspiration in clear days were around $3.0 \mathrm{~mm} \mathrm{day}^{-1}$. Summarily, the closed-path system underestimates evapotranspiration a few percent when compared with $\mathrm{ET}_{\mathrm{op}}\left(\mathrm{ET}_{\mathrm{op}}=1.05\right.$ $\left.\mathrm{ET}_{\mathrm{cp}}, R^{2}=0.91, n=247\right)$. Cumulative evapotranspiration in 2003 in the old-growth mixed forest at Changbai Mountains site was $493 \pm 45 \mathrm{~mm}$ for the OP system and $469 \pm 39 \mathrm{~mm}$ for the CP system. Overall differences between open- and closed- path systems appeared to be systematic and lead to around $5.1 \%$ discrepancy of cumulative annual evapotranspiration.

\section{Discussion}

The eddy covariance method has become one of the most common methods for measuring $\mathrm{H}_{2} \mathrm{O}$ and $\mathrm{CO}_{2}$ fluxes as it makes direct measurements and can be used at different spa- 
tial scales. The objective of this paper is to assess the performance of open- and closed path eddy covariance system in long-term water vapor flux measurements over forest.

\subsection{Post-processing of eddy covariance data}

Generally, open-path eddy covariance system need less maintenance as compared to closed path systems (Haslwanter et al., 2009) and are more suited for field stations without power supply. Practically, the main drawback of the OP system is that considerable data collected during precipitation, dew or fog must be removed, which increases the uncertainty of the annual flux estimates (Moffat et al., 2007). However, the current study found that there was a correspondingly large fraction of unaccepted data from CP system too. Over $15 \% L E_{\mathrm{cp}}$ data was rejected mainly due to failing in the integral turbulence and stationarity test. The $\mathrm{CP}$ system measured fluxes during the rainfall period are also questionable, considering that the high humidity conditions could lead to significant bias in fluxes estimations. Through six year-round observations in a temperate mountain grassland flux site, Haslwanter et al. (2009) also found that only $36 \%$ and $33 \%$ of water vapor fluxes for the CP and OP observed data, respectively, passed all quality control tests, and the large gap difference between the $\mathrm{CP}$ and OP system due to the interference of precipitation or droplets was mostly counterbalanced by the stationarity test, which eliminated $28-36 \%$ of the CP, but only $19-21 \%$ of the OP data. Therefore, careful system design and adequate maintenance is required for both open- and closed-path systems to ensure obtaining high and continuous good data coverage in longterm water vapor flux measurements.

Both OP- and CP system have different errors and biases. Hence eddy correlation measurements require substantial post-field data corrections. But currently, there are no unified standards across the available methods for handling the flux data. For the CP system, post-processing of eddy covariance data has been widely discussed in terms of water vapor attenuation in the tube, but less attention is given to the effects of tube delay (Ibrom et al., 2007a, b). The eddy covariance method assumes that vertical wind velocity and scalar concentrations are measured at the same point in space. While in practice, due to sensor separation of sonic anemometer and infrared gas analyze, tube delay exists when the air travels from the intake to the measurement cell of the analyzer. For simplicity in $\mathrm{CO}_{2}$ flux calculation, the time lag could be considered as a constant. However the lag time of closed-path water vapor measurements is related to relative humidity, and much longer water vapor flux time lags tend to occur during higher relative humidity periods. In case of the Changbai Mountains forest flux site, the tube delay in CP system was determined using optimized covariance maximization method ranging from 5.3 to $37.6 \mathrm{~s}$. Nordbo (2012) found a similar relative humidity dependency for a $41 \mathrm{~m}$ steel sampling tube, with lag times ranging approximately from 7.1 to $39.9 \mathrm{~s}$.

To test the sensitivity of flux estimation to the time lag, three compensation schemes of time lag were used in water vapor flux calculation. The fixed median delay of $8.6 \mathrm{~s}$ results in an underestimation of $L E$ by average of $5.3 \%$ compared to the fluxes calculated with the optimized time lags for each $30 \mathrm{~min}$ averaging interval. On the other hand, the widely used conventional covariance maximum method with a single broad time lag search window results in slight overestimation of water vapor fluxes. The discrepancy is small but noticeable because it is a systematic error, and hence has certain consequences for the accumulated water fluxes between forest and atmosphere. These results indicate that the tube delay for each averaging interval have to be taken into account carefully in processing of eddy covariance data from CP system.

The time delay correction of CP system was analysis here as an example to illustrate that the uncertainty associated with the eddy correlation based water vapor estimations may originate from post-field data processing. The quantitative results are only valid for the specific forest flux site in northeastern China, while the qualitative conclusions can be extrapolated to the other sites performing eddy covariance measurements, especially for the forest flux sites with relatively high humidity and long sampling tube.

\subsection{Comparisons between $\mathrm{CP}$ and $\mathrm{OP}$ water vapor flux measurements}

The measurement uncertainty associated with the eddy covariance technique is complicated. Both open- and closedpath eddy covariance systems have different errors and biases. It is generally accepted that one of a dominant source of biases is related to flux attenuation in the tube of CP system. In this study, overall differences between open- and closedpath systems appear to be systematic and which leads to a remarkable difference of cumulative annual evapotranspiration. The compensated time lags with optimized covariance maximization method slightly decrease the annual evapotranspiration estimation from $\mathrm{CP}$ system, this little reduction can not account for the discrepancy between the open- and closed-path systems. Kosugi and Katsuyama (2007) reported that eddy covariance method underestimated the short-term evapotranspiration for both the open- and closed- path systems, and the situation was worse in the CP system. Haslwanter et al. (2009) also found that the CP system tended to underestimate water vapor fluxes above grassland. In contrast, Ocheltree and Loescher (2007) compared open- and closed-path gas analyzer measurements of $\mathrm{CO}_{2}$ fluxes and reported good agreement $\left(R^{2}=0.96\right)$ between them. Suyker and Verma (1993) found CP system based $\mathrm{CO}_{2}$ flux overestimation, but well within $5 \%$ when compared to OP system. These comparisons suggest that unlike the well performance on $\mathrm{CO}_{2}$ flux measurements, there is a systematic difference 

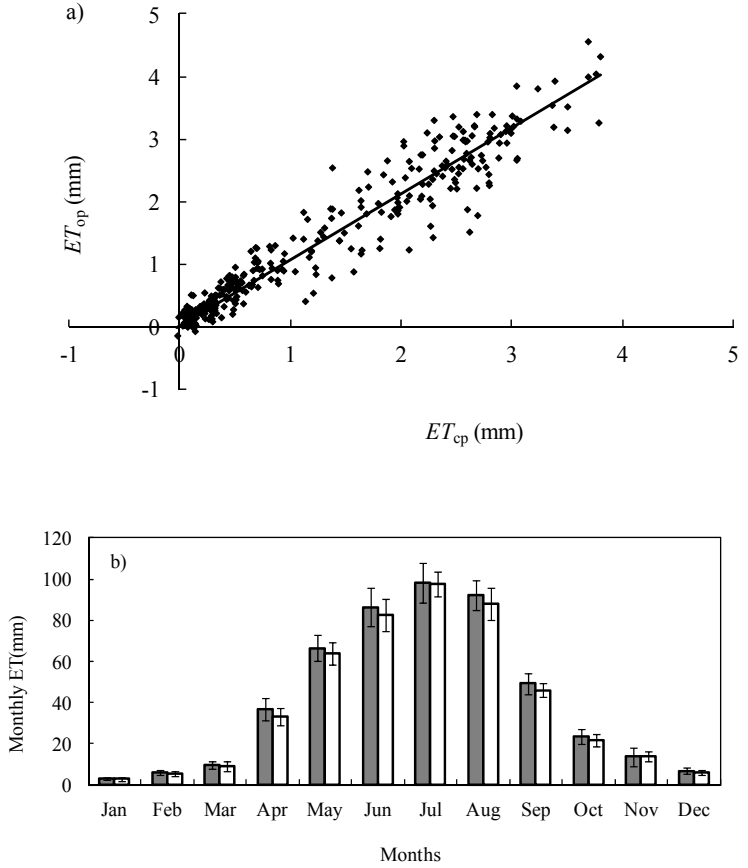

Figure 7. Energy balance closure for the OP (a) and CP system (b). Plotted are the available energy (net radiation minus soil heat flux) on the $x$ axis and the sum of sensible and latent heat flux on the $y$ axis. Symbols represent half-hourly fluxes, broken lines the $1: 1$ correspondence, and solid lines linear regressions.

between $\mathrm{OP}$ - and $\mathrm{CP}$ system for water vapor flux measurements.

The tower measurements rarely close the energy budget resulting in non-closure on the order of $20 \%$ (Wilson et al., 2002). The underestimation for CP system potentially results in a more serious energy balance closure problem. The ability of the two systems to close the energy balance was assessed by comparing the available energy, that is the net radiation $\left(R_{\mathrm{n}}\right)$ minus the soil heat flux $(G)$, with the sum of the latent and sensible heat $(H)$, as shown in Fig. 7. Differences in energy balance closure between the OP $\left(H+L E=0.82\left(R_{\mathrm{n}}-G\right)+16.40, r^{2}=0.84\right)$ and the CP $\left(H+L E=0.79\left(R_{\mathrm{n}}-G\right)+14.86, r^{2}=0.86\right)$ system are remarkable for the growing season data, with a more favorable closure for the OP system. This indicates that there is a systematic difference (approx. 3.0\%) in energy balance closure between $\mathrm{OP}$ and $\mathrm{CP}$ systems.

The $L E_{\mathrm{cp}}$ comparisons in Fig. 4 indicate that the closure condition could be even worse when a fixed time delay is used. Usage of the time lags calculated from the conventional covariance maximum method with single time lag search window contributes to partial make up for the imbalance of energy closure, while the possibility of $L E_{\mathrm{cp}}$ overestimation also exists for this compensation scheme. Therefore more effort is needed to identify and quantify the uncertainties associated with flux measurements.

\section{Conclusions}

To explore the hydrological processes in terrestrial ecosystems, it requires accurately measuring the rates of water vapor loss from the terrestrial ecosystem to the atmosphere. An open- and a closed-path system were installed for longterm $\mathrm{CO}_{2} / \mathrm{H}_{2} \mathrm{O}$ flux measurements over a temperate forest in northeastern China. The specific performance of these two systems on latent heat flux measurements was intercompared by using a year-round data set. Compared to water vapor fluxes calculated with optimized lag time, using a fixed lag time could cause a significant underestimation (averagely around $5.3 \%$ ) of $L E_{\mathrm{cp}}$ in magnitude, while slight systematic overestimation was also found for covariance maximization method with a single broad time lag search window. It is therefore important to estimate the lag time accurately for flux calculations with closed-path analyzers. The comparative measurements of water vapor fluxes between open- and closed-path eddy covariance systems indicated that the $L E_{\mathrm{cp}}$ was generally underestimated, whereas it was very consistent with that of $L E_{\mathrm{op}}$ in daily and seasonal pattern. We concluded that both the closed-path and open path analyzer is reliable for long-term measurements of water vapor flux over the tall forest, while more attentions should be paid on the compensations of flux losses from CP system. This study indicates the importance to estimate the sampling tube delay accurately for water vapor flux calculations with closed-path analyzers, and it also indicates that some of the imbalance of the surface energy budget in fluxes sites is possibly caused by the systematic underestimation of water vapor fluxes measured with closed-path eddy covariance systems.

\section{The Supplement related to this article is available online at doi:10.5194/amt-8-4123-2015-supplement.}

Acknowledgements. This study was jointly financed by the State Key Development Program of Basic Research (2013CB429902), and the State Key Laboratory of Forest and Soil Ecology (Grant No. LFSE2013-11). The authors are deeply grateful to the staff of the National Forest Ecosystem Research Station of the Changbai Mountains for their assistance in the maintenance of instruments and collection of field data.

Edited by: D. Heard

\section{References}

Aubinet, M., Grelle, A., Ibrom, A., Rannik, U., Moncrieff, J., Foken, T., Kowalski, A. S., Martin, P. H., Berbigier, P., Bernhofer, Ch., Clement, R., Elbers, J., Granier, A., Grünwarld, T., Morgenstern, K., Pilegaard, K., Rebmann, C., Snijders, W., Valentini, R., and Vesala, T.: Estimates of the annual net carbon and water exchange of forest: the EUROFLUX methodology, Adv. Ecol. Res., $30,113-175,2000$. 
Baldocchi, D., Falge, E., Gu, L. H., Olson, R., Hollinger, D., Running, S., Anthoni, P., Bernhofer, C., Davis, K., Evans, R., Fuentes, J., Goldstein, A., Katul, G., Law, B., Lee, X. H., Malhi, Y., Meyers, T., Munger, W., Oechel, W., Paw, U. K. T., Pilegaard, K., Schmid, H. P., Valentini, R., Verma, S., Vesala, T., Wilson, K., and Wofsy, S.: FLUXNET: A new tool to study the temporal and spatial variability of ecosystem-scale carbon dioxide, water vapor, and energy flux densities, B. Am. Meteorol. Soc., 82, 2415-2434, 2001.

Burba, G., McDermitt, D., Grelle, A., Anderson, D. J., and Xu, L. $\mathrm{K}$.: Addressing the influence of instrument surface heat exchange on the measurements of $\mathrm{CO}_{2}$ flux from open-path gas analyzers, Glob. Change Biol., 14, 1854-1876, 2008.

Consoli, S. and Vanella, D.: Comparisons of satellite-based models for estimating evapotranspiration fluxes, J. Hydrol., 513, 475489, 2014

Fan, S. M., Wofsy, S. C., Bakwin, P. S., Jacob, D. J., and Fitzjarrald, D. R.: Atmosphere-biosphere exchange of $\mathrm{CO}_{2}$ and $\mathrm{O}_{3}$ in the Central Amazon Forest, J. Geophys. Res., 95, 16851-16864, 1990.

Foken, T. and Wichura, B.: Tools for quality assessment of surfacebased flux measurements, Agr. Forest Meteorol., 78, 83-105, 1996.

Fratini, G., Ibrom, A., Arriga, N., Burba, G., and Papale, D.: Relative humidity effects on water vapour fluxes measured with closed-path eddy-covariance systems with short sampling lines, Agr. Forest Meteorol., 165, 53-63, 2012.

Haslwanter, A., Hammerle, A., and Wohlfahrt, G.: Open- vs. closedpath eddy covariance measurements of the net ecosystem carbon dioxide and water vapour exchange: a long-term perspective, Agr. Forest Meteorol., 149, 291-302, 2009.

Horst, T. W. and Lenschow, D. H.: Attenuation of scalar fluxes measured with spatially-displaced sensors, Bound.-Lay. Meteorol., 130, 275-300, 2009.

Ibrom, A., Dellwik, E., Jensen, N. O., Flyvbjerg, H., and Pilegaard, K.: Strong low-pass filtering effects on water vapour flux measurements with closed-path eddy correlation systems, Agr. Forest Meteorol., 147, 140-156, 2007a.

Ibrom, A., Dellwik, E., Larsen, S. E., and Pilegaard, K.: On the use of the Webb-Pearman-Leuning theory for closed-path eddy correlation measurements, Tellus B, 59, 937-946, 2007b.

Jarvi, L., Mammarella, I., Eugster, W., Iborm, A., Siivola, E., Dellwik, E., Keronen, P., Burba, G., and Vesala, T.: Comparison of net $\mathrm{CO}_{2}$ fluxes measured with open- and closed-path infrared gas analyzers in an urban complex environment, Boreal Environ. Res., 14, 499-514, 2009.

Kondo, F. and Tsukamoto, O.: Comparative $\mathrm{CO}_{2}$ flux measurements by eddy covariance technique using open- and closed-path gas analysers over the equatorial Pacific Ocean, Tellus B, 64, 17511, doi:10.3402/tellusb.v64i0.17511, 2012.

Kosugi, Y. and Katsuyama, M.: Evapotranspiration over a Japanese cypress forest, II, comparison of the eddy covariance and water budget methods, J. Hydrol., 334, 305-311, 2007.

Lee, X.: On micrometeorological observations of surface-air exchange over tall vegetation, Agr. Forest Meteorol., 91, 39-49, 1998.

Lee, X., Black, A., and Novak, M. D.: Comparison of flux measurements with open- and closed-path gas analyzers above an agricultural field and a forest floor, Bound.-Lay. Meteorol., 67, 195-202, 1994.

Leuning, R. and Judd, M.: The relative merits of open- and closedpath, Glob. Change Biol., 2, 241-253, 1996.

Leuning, R. and King, K. M.: Comparison of eddy-covariance measurements of $\mathrm{CO}_{2}$ fluxes by open- and closed-path $\mathrm{CO}_{2}$ analysers, Bound-Lay. Meteorol., 59, 297-311, 1992.

Leuning, R. and Moncrieff, J.: Eddy-covariance CO flux measurements using open- and closed-path $\mathrm{CO}_{2}$ analysers: corrections for analyser water vapour sensitivity and damping of fluctuations in air sampling tubes, Bound.-Lay. Meteorol, 53, 63-76, 1990.

Massman, W. J.: The attenuation of concentration fluctuations in turbulent flow through a tube, J. Geophys. Res., 96, 1525915268, 1991.

Massman, W. J. and Lee, X.: Eddy covariance flux corrections and uncertainties in long-term studies of carbon and energy exchanges, Agr. Forest Meteorol., 113, 121-144, 2002.

Moffat, A. M., Papale, D., Reichstein, M., Hollinger, D. Y., Richardson, A. D., Barr, A. G., Beckstein, C., Braswell, B. H., Churkina, G., Desai, A. R., Falge, E., Gove, J. H., Heimann, M., Hui, D. F., Jarvis, A. J., Kattge, J., Noormets, A., and Stauch, V. J.: Comprehensive comparison of gap-filling techniques for eddy covariance net carbon fluxes, Agr. Forest Meteorol., 147, 209-232, 2007.

Moncrieff, J. B., Clement, R., Finnigan, J., and Meyers, T.: Averaging, detrending and filtering of eddy covariance time series, in: Handbook of micrometeorology: a guide for surface flux measurements, edited by: Lee, X., Massman, W. J., and Law, B. E., Kluwer Academic Press, Dordrecht, the Netherlands, 7-31, 2004.

Nordbo, A., Jarvi, L., and Vesala, T.: Revised eddy covariance flux calculation methodologies - effect on urban energy balance, Tellus B, 64, 18184, doi:10.3402/tellusb.v64i0.18184, 2012.

Ocheltree, T. W. and Loescher, H. W.: Design of the AmeriFlux Portable Eddy Covariance System and Uncertainty Analysis of Carbon Measurements, J. Atmos. Ocean. Tech., 24, 1389-1406, 2007.

Suyker, A. E. and Verma, S. B.: Eddy correlation measurements of $\mathrm{CO}_{2}$ flux using a closed-path sensor: theory and field test against an open-path sensor, Bound.-Lay. Meteorol., 64, 391-407, 1993.

van Dijk, A., Moene, A. F., and de Bruin, H. A. R.: The principles of surface flux physics: Theory, practice and description of the ECPack library, Meteorology and Air Quality Group, Wageningen University, Wageningen, the Netherlands, 99 pp., 2004.

Vinukollu, R. K., Wood, E. F., Ferguson, C. R., and Fisher, J. B.: Global estimates of evapotranspiration for climate studies using multi-sensor remote sensing data: evaluation of three processbased approaches, Remote Sens. Environ., 115, 801-823, 2011.

Webb, E. K., Pearman, G. I., and Leuning, R.: Correction of flux measurements for density effects due to heat and water vapour transfer, Q. J. Roy. Meteor. Soc., 106, 85-100, 1980.

Wilson, K. B, Goldstein, A., and Falge, E.: Energy balance closure at FLUXNET sites, Agr. Forest Meteorol., 113, 223-243, 2002.

Yasuda, Y. and Watanabe, T.: Comparative measurement of $\mathrm{CO}_{2}$ flux over a forest using closed-path and open-path $\mathrm{CO}_{2}$ analysers, Bound.-Lay. Meteorol., 100, 191-208, 2001. 